\title{
Prognostic Significance of Hyponatremia in ST- elevation Myocardial Infarction/Heart Failure Patients
}

\author{
Vraj Shah ${ }^{1}$, Nusrat Jahan ${ }^{2}$ \\ 1. Cardiology, California Institute of Behavioral Neurosciences and Psychology, Fairfield, USA 2. Internal Medicine, \\ California Institute of Behavioral Neurosciences and Psychology, Fairfield, USA
}

Corresponding author: Nusrat Jahan, drnusrat30@hotmail.com

\begin{abstract}
ST-elevation myocardial infarction (STEMI) and heart failure (HF) are common, big-budget, debilitating and expanding diseases. Cardiovascular diseases, especially STEMI and heart failure have been known to cause 17.3 million deaths worldwide annually. Hyponatremia, delineated as a serum sodium (sNa) concentration $<135 \mathrm{mmol} / \mathrm{l}$, is a frequently seen electrolyte disturbance in practice and the prevalence, clinical impact; the prognostic factor of low SNa in STEMI/heart failure patients vary widely. The aim of this review is to assess its existence and comparing survival difference between hypo and normonatremic patients.
\end{abstract}

A comprehensive review of the published articles was conducted using database PubMed. We found a total of over 1400 articles. The inclusion criteria used for this review were age $>65$ years, published within the last 10 years, written in English, performed on human subjects and of studies such as reviews and randomized controlled trials (RCTs), especially for heart failure MeSH words. By applying this inclusion criterion, we found out 40 relevant articles which included 26 cohort studies, four clinical trials, four review articles, and six RCTs. In the analysis of 7,06,899 patients with STEMI/heart failure, hyponatremia was significantly linked to causing all-cause mortality, both short and long term (hazard ratio [HR] as continuous variable: 1.06; 95\% confidence interval [CI]: 1.01-1.11; P = 0.026; HR as categorical variable: $1.71 ; 95 \%$ CI: 1.06-2.75; P $=0.028$ ). The rates of rehospitalization were also higher (odds ratio, 1.68 ; $95 \%$ confidence interval, $1.32-$ 2.14) along with prolonged hospital stays as well as a greater cost burden as compared to patients with normal serum sodium. It was existent not only in patients with reduced ejection fraction (HFrEF) but also in subjects with preserved ejection fraction (HFpEF) (HR 1.40, 95\% CI 1.12 to $1.75, \mathrm{P}=0.004$ ). Rise of first follow-up and discharge sodium does seem to have positive linkage on survival as well (hazard ratio [HR] 0.429, 95\% CI 0.191-0.960, $\mathrm{P}=0.04)$.

Hyponatremia is the most frequently encountered electrolyte abnormality in clinical practice and has a poor prognosis in both STEMI and heart failure patients. It exacerbates both short and long term mortality, rehospitalization rates, as well as the average length of stay in the hospital. Although it is still a mystery whether hyponatremia is just a marker of iller patients or the core of poor prognosis in patients with STEMI and HF, one thing is certain: timely recognition of patients at risk for developing hyponatremia could help to commence early treatment.

Received 08/23/2019

09/03/2019 Review ended 09/04/2019 Published 09/16/2019

(c) Copyright 2019

Shah et al. This is an open access article distributed under the terms of the Creative Commons Attribution License CC-BY 3.0., which permits unrestricted use, distribution, and reproduction in any medium, provided the original author and source are credited.
Categories: Cardiology, Internal Medicine

Keywords: stemi, hyponatremia, heart failure

\section{Introduction And Background}

According to McMurray et al., ST-elevation myocardial infarction (STEMI) and heart failure (HF) are common, big-budget, debilitating, and expanding diseases [1]. Cardiovascular diseases, especially STEMI and heart failure have been known to cause 17.3 million deaths worldwide annually [2-4]. Hyponatremia, which refers to a serum sodium ( $\mathrm{sNa}$ ) concentration $<135 \mathrm{mmol} / \mathrm{l}$, is a common electrolyte disturbance that is seen frequently in clinical practice. Moreover, previous studies have shown the prevalence of hyponatremia in patients suffering from STEMI ranges between $12.5 \%-23.2 \%$ [5] and close to $25 \%$ in patients with HF [6].

Several mechanisms can explain the occurrence of hyponatremia in these patients, such as neurohormonal activation of the renin-angiotensin-aldosterone system (RAAS) as well as sympathetic overstimulation due to reduced stroke volume and subsequent underfilling of arteries [7-9]. Several observational studies and clinical trials have been carried out to appraise the prognostic impact of serum sodium levels at admission and during hospitalization of STEMI and HF patients. Accordingly, a strong alliance is established between the mortality of STEMI, HF patients and low sNa status at admission. Although it is still a mystery whether hyponatremia is just a marker of more ill patients or the core factor of poor prognosis in patients with STEMI and HF, one thing is certain: timely recognition of patients at risk for developing hyponatremia could help to commence earlier treatment. 


\section{Cureus}

The aim of this review is to identify the prognostic significance of hyponatremia in STEMI and HF patients, heart failure with both preserved (HFpEF) and reduced ejection fraction (HFrEF), and whether the correction of serum sodium during hospitalization and discharge could improve both short and long term adverse outcomes such as all-cause mortality, cardiac-specific mortality, rehospitalization, length of hospital stay, diuretic resistance as well as signs and symptoms.

\section{Review}

A comprehensive review of published literature in PubMed was conducted in order to study the prognostic significance of hyponatremia in STEMI and HF patients. Articles included were those relevant to the theme of hyponatremia, STEMI and HF. A search was conducted using database PubMed with MeSH keywords such as hyponatremia, STEMI, and heart failure and subheadings such as analysis and mortality which gave us $1,254,847$ and 8,339 articles respectively. The inclusion criteria used for this review were age $>65$ years, published within the last 10 years, written in English, conducted on human subjects and included studies of reviews and randomized controlled trials (RCT) for heart failure MeSH word particularly. Yet, the total came to over 1400 articles after applying inclusion criteria. Out of these, there was a repetition involving 18 articles. A total of 40 pieces of literature were appropriate for this analysis. Out of these, 30 were included using their abstracts while 10 were included using full review. Among them, 26 were identified themselves as cohort studies (including 19 identified as a retrospective cohort and seven identified as a prospective cohort) [5, 10-34], four were review articles [35-38], four were clinical trials [39-42], and six identified themselves as RCTs [43-48]. A total of 70,6899 subjects comprise the study population. Table 1 shows the total number of articles obtained after applying inclusion criteria for MeSH keywords in PubMed. Table 2 shows appropriate articles for the literature review with the total number of study subjects.

\begin{tabular}{|c|c|c|c|}
\hline Articles & Results & Results & Results \\
\hline MeSH words & Hyponatremia & STEMI & Heart failure \\
\hline Total articles & 1254 & 847 & 8339 \\
\hline Year of publication ( $<10$ years) & 615 & 847 & 4089 \\
\hline Species (humans) & 599 & 843 & 3960 \\
\hline Language (English) & 565 & 827 & 3733 \\
\hline Age $(>65)$ & 297 & 601 & 2445 \\
\hline Study type (review, RCT) & - & - & 509 \\
\hline Final articles & 297 & 601 & 509 \\
\hline
\end{tabular}

\section{TABLE 1: Keywords search after applying inclusion criteria in PubMed}

Articles appropriate for the literature review

Articles included using abstract

Articles included using full text

Total number of study subjects

\section{0}

30

10

$7,06,899$

TABLE 2: Articles appropriate for the literature review, and the Total number study subjects.

Based on study results, hyponatremia was significantly associated with short-term as well as long-term mortality in these patients. Rates of rehospitalization were also on a higher side as compared to patients with normal serum sodium. The average length of hospital stay and cost burden was much more. These findings were not only accurate for patients with preserved ejection fraction but also patients with reduced ejection fraction $[5,10-48]$.

In this analysis of 706,899 patients, we examined the interconnection between serum sodium and prognosis in STEMI and HF patients. A significant association was noted between serum sodium and outcome. As compared to normonatremia, hyponatremia was remarkably associated with poor prognosis in these study subjects. 
In most studies, hyponatremia was found to be a standalone predictor of death in HF patients. In the current literature review, there was an immense and independent association between hyponatremia and term mortality (both short and long term, cardiac-specific and all-cause). The average length of hospital stay was prolonged in hyponatremic subjects than patients with normal sNa levels. Because it is a poor prognostic indicator and measure of the quality of life and cost, rehospitalization is usually included either alone or belonging to a composite clinical endpoint in studies examining various aspects of STEMI and HF. Based on study results, patients with low sNa levels had higher rehospitalization rates than normonatremic patients in our analysis. STEMI and HF patients with persistent low serum sodium, i.e., present both on admission and at discharge, have the highest mortality and rehospitalization rates compared with all-time normonatremia and the rise of first follow-up and discharge of sodium are positively correlated. These differences were significant in this study. This is concordant with previously reported studies emphasizing this same problem. It was evident even in patients with preserved ejection fraction. Table 3 shows the analysis of various studies such as cohort, RCT, and review.

\begin{tabular}{|c|c|c|c|}
\hline $\begin{array}{l}\text { Author } \\
\text { name/YOP }\end{array}$ & Study design & $\begin{array}{l}\text { Sample } \\
\text { size }\end{array}$ & Main points \\
\hline $\begin{array}{l}\text { Rusinaru et } \\
\text { al., } 2012 \text { [37] }\end{array}$ & $\begin{array}{l}\text { Systematıc } \\
\text { review }\end{array}$ & 11301 & $\begin{array}{l}\text { Hyponatraemia has been negatively linked to heart failure patients with HFrEF. The connection } \\
\text { between serum sodium and prognosis is unclear in heart failure with preserved }(\geq 50 \%) \text { ejection } \\
\text { fraction (HFpEF). BY analyzing 14,766 patients from } 22 \text { studies, hyponatremia was solely predictive of } \\
\text { demise in both HFrEF [adjusted hazard ratio (HR) 1.69] and HFpEF (adjusted HR 1.40, } 95 \% \text {, P for } \\
\text { interaction } 0.20 \text { ). }\end{array}$ \\
\hline $\begin{array}{l}\text { Bavishi et } \\
\text { al., } 2014 \text { [21] }\end{array}$ & $\begin{array}{l}\text { Prospective } \\
\text { cohort study }\end{array}$ & 8862 & $\begin{array}{l}\text { Hyponatremia happens to be negatively linked in hospitalized patients with reduced ejection fraction. } \\
\text { Still, there is insufficient information in roaming subjects with HF with preserved ejection fraction. By } \\
\text { evaluating the prevalence, risk factors, and long-term outcomes of hyponatremia in ambulatory } \mathrm{HFpEF} \\
\text { and } \mathrm{HFrEF} \text { in a cohort of } 8,862 \text { veterans. Hyponatremia is present at a similar frequency of over } 10 \% \text { in } \\
\text { ambulatory patients with } \mathrm{HFpEF} \text { and HFrEF. Hyponatremia is a sole prognostic marker of mortality } \\
\text { across the spectrum of patients with HFpEF and HFrEF. In contrast, it is an independent predictor for } \\
\text { hospitalization in patients with HFrEF along with HFpEF. }\end{array}$ \\
\hline $\begin{array}{l}\text { Abebe et al., } \\
2018 \text { [9] }\end{array}$ & $\begin{array}{l}\text { Retrospective } \\
\text { cohort study }\end{array}$ & 388 & $\begin{array}{l}\text { Hyponatremia is shown to be negatively linked in STEMI and HF patients. It is significantly associated } \\
\text { with death in advanced age. Hyponatremia is one of the major elements in the clinical outcome of heart } \\
\text { failure subjects. }\end{array}$ \\
\hline $\begin{array}{l}\text { Hiki et al., } \\
2018 \text { [10] }\end{array}$ & $\begin{array}{l}\text { Retrospective } \\
\text { cohort study }\end{array}$ & 34 & $\begin{array}{l}\text { Hyponatremia carries a poor prognosis in HF patients. There is a paucity of data regarding the value. } \\
\text { This analysis showed increased rates of rehospitalization as well as mortality(both short-term and long- } \\
\text { term) even with low-normal sodium levels. }\end{array}$ \\
\hline $\begin{array}{l}\text { Qureshi et } \\
\text { al., } 2013 \text { [23] }\end{array}$ & $\begin{array}{l}\text { Retrospective } \\
\text { cohort study }\end{array}$ & 562 & $\begin{array}{l}\text { Hyponatremia has a strong positive linkage in patients with HF. However, insufficient data is there } \\
\text { regarding its significance in patients presenting with STEMI. After retrospectively analyzing } 11,562 \\
\text { subjects, our analysis showed that corrected and persistent hyponatremia in patients presenting with } \\
\text { STEMI has been negatively linked to all-cause mortality both short-term and long-term and higher rates } \\
\text { of rehospitalization. In certain subjects, timely correction of hyponatremia may ameliorate the survival } \\
\text { of the patients. }\end{array}$ \\
\hline $\begin{array}{l}\text { Baldasseronı } \\
\text { et al., } 2011 \\
\text { [27] }\end{array}$ & $\begin{array}{l}\text { Retrospective } \\
\text { cohort study }\end{array}$ & 370 & $\begin{array}{l}\text { It has been proven that low serum sodium carries worse prognosis in HF and STEMI subjects. We } \\
\text { analyzed } 4670 \text { patients signed up in the IN-CHF registry. Mild-to-moderate and severe hyponatremia } \\
\text { (groups two and three) solely predicted first-year death. The connection between sodium } \\
\text { concentration and demise was not linear and a drop of } 1 \mathrm{mEq} / \mathrm{l} \text { of sodium exacerbated death rate only } \\
\text { for merits of sodium } 142.9 \mathrm{mEq} / \mathrm{l} \text { or less. This relationship was not modified by beta-blocker and ACE } \\
\text { inhibitor therapies. }\end{array}$ \\
\hline $\begin{array}{l}\text { Mohammed } \\
\text { et al., } 2010 \\
\text { [31] }\end{array}$ & $\begin{array}{l}\text { Retrospective } \\
\text { cohort study }\end{array}$ & 628 & $\begin{array}{l}\text { A total of } 628 \text { subjects who came to the emergency department with acutely decompensated heart } \\
\text { failure were studied who were hospitalized. In multivariate Cox proportional hazards analysis showed } \\
\text { hyponatremia to be an independent predictor of first-year demise (hazards ratio }=1.72 ; 95 \% \mathrm{Cl}=1.22 \text { to } \\
2.37 ; \mathrm{P}=0.001 \text { ) as was an NT-proBNP concentration above the median value of } 4690 \mathrm{pg} / \mathrm{mL} \text { (hazards } \\
\text { ratio=1.49; } 95 \% \mathrm{Cl}=1.10 \text { to } 2.00 ; \mathrm{P}=0.009 \text { ). Subjects with low } \mathrm{SNa} \text { and severely elevated NT-proBNP } \\
\text { were much likely to evolve worsening kidney function during their course of hospital stay and had the } \\
\text { highest first-year demise rates. }\end{array}$ \\
\hline $\begin{array}{l}\text { Mendez- } \\
\text { Bailón et al., } \\
2015[18]\end{array}$ & $\begin{array}{l}\text { Retrospective } \\
\text { cohort study }\end{array}$ & 504860 & $\begin{array}{l}\text { This analysis assessed the incidence, average length of stay, comorbidities, rates of readmissions and } \\
\text { deaths caused by hyponatremia in admissions for acute heart failure from the MBDS. A total of } \\
5,04,860 \text { patients with acute heart failure were enrolled, of whom } 11,095(2.2 \%) \text { appeared with } \\
\text { sNa.Overall deaths due to any cause in subjects with hyponatremia were } 17 \% \text { ( } 1937 \text { patients) versus } \\
11 \% \text { in normonatremic patients ( } 53,820 \text { patients). The probability of rehospitalization for patients with } \\
\text { hyponatremia was } 22 \% \text { versus } 17 \% \text { in normonatremic group. Hyponatremia was negatively linked with } \\
\text { mortality during hospitalization for acute heart failure with an odds ratio (OR) of } 1.58,95 \% \mathrm{Cl}, 1.50-1.66\end{array}$ \\
\hline
\end{tabular}




\section{Cureus}

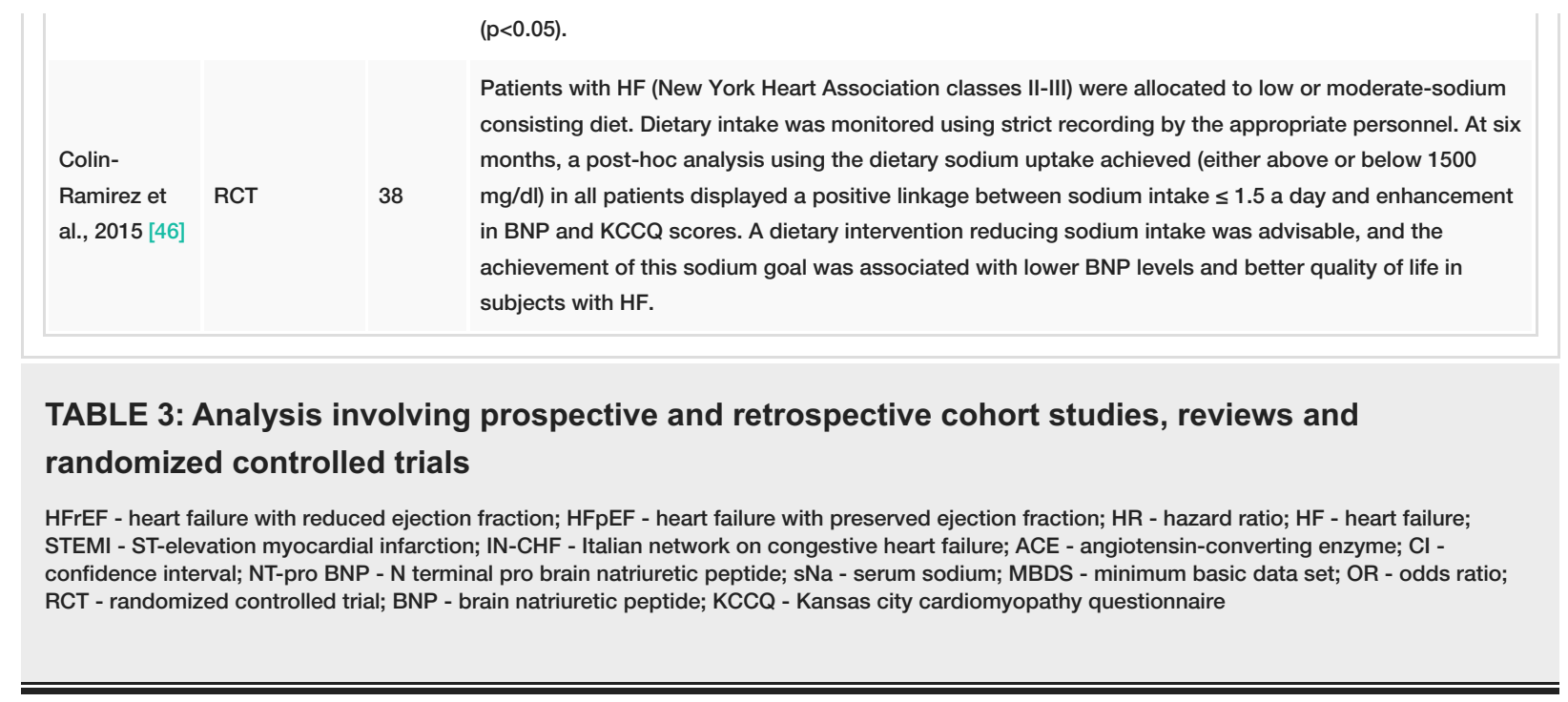

All randomized clinical trials, retrospective, and prospective cohort studies, as well as reviews, reveal a strong association between serum sodium and prognosis. Collectively, these data do provide sufficient evidence that low sNa carries worse prognosis in these patients.

Various mechanisms contribute to low serum sodium in these patients such as low stroke volume, low cardiac output with subsequent underfilling of arterioles and activation of RAAS, the non-osmotic release of vasopressin and severe sympathetic stimulation causing water retention, vasoconstriction causing dilutional hyponatremia. The level of serum sodium may affect the transmembrane potentials in heart cells, the formation of regulatory proteins, enzymes and muscle excitation.

The current literature review did not include STEMI and HF patients below 65 years with hyponatremia, hyponatremia associated with diabetes, advanced age, increase blood urea nitrogen and diuretics. After adjusting for these variables, the results could have been altered. However, one thing is certain that the dynamic monitoring of serum sodium could help physicians identify these high-risk patients and stratify risk for optimal management.

\section{Conclusions}

Hyponatremia is the most frequently encountered electrolyte abnormality in clinical practice carries poor prognosis in both STEMI and HF patients. It exacerbates both short- and long-term mortality, rehospitalization rates, the average length of stay in the hospital. The rise of first follow-up sodium during hospitalization as well as during discharge is linked with better outcomes. It is prevalent not only in patients with reduced ejection fraction but also in preserved ejection fraction. Although it is still a mystery whether hyponatremia is just a marker of more ill patients or core of the problem, intense monitoring of sNa could help physicians and researchers optimizing appropriate treatment regimen and to stratify risk management.

\section{Additional Information}

\section{Disclosures}

Conflicts of interest: In compliance with the ICMJE uniform disclosure form, all authors declare the following: Payment/services info: All authors have declared that no financial support was received from any organization for the submitted work. Financial relationships: All authors have declared that they have no financial relationships at present or within the previous three years with any organizations that might have an interest in the submitted work. Other relationships: All authors have declared that there are no other relationships or activities that could appear to have influenced the submitted work.

\section{References}

1. McMurray JV, Pfeffer MA: Heart failure. Lancet. 2005, 365:1877-1889.

2. Laslett LJ, Alagona P Jr., Clark BA 3rd, et al.: The worldwide environment of cardiovascular disease: prevalence, diagnosis, therapy, and policy issues. J Am Coll Cardiol. 2012, 60:S1-S49. 10.1016/j.jacc.2012.11.002

3. Rapsomaniki E, Timmis A, George J, et al.: Blood pressure and incidence of twelve cardiovascular diseases: lifetime risks, healthy life-years lost, and age-specific associations in 1.25 million people. Lancet. 2014, 383:1899-911. 10.1016/s0140-6736(14)60685-1

4. Roth GA, Huffman MD, Moran AE, Feigin V, Mensah GA, Naghavi M, Murray CJ: Global and regional patterns in cardiovascular mortality from 1990 to 2013. Circulation. 2015, 132:1667-78. 10.1161/CIRCULATIONAHA.114.008720

5. Madan VD, Novak E, Rich MW: Impact of change in serum sodium concentration on mortality in patients 
hospitalized with heart failure and hyponatremia. Circ Heart Fail. 2011, 4:637-43.

10.1161/CIRCHEARTFAILURE.111.961011

6. Mohan S, Gu S, Parikh A, Radhakrishnan J: Prevalence of hyponatremia and association with mortality: results from NHANES. Am J Med. 2013, 126:1127-37. 10.1016/j.amjmed.2013.07.021

7. Fraccarollo D, Galuppo P, Hildemann S, Christ M, Ertl G, Bauersachs J: Additive improvement of left ventricular remodeling and neurohormonal activation by aldosterone receptor blockade with eplerenone and ACE inhibition in rats with myocardial infarction. J Am Coll Cardiol. 2003, 42:1666-73. 10.1016/j.jacc.2003.05.003

8. Sigurdsson A, Swedberg K: Left ventricular remodeling, neurohormonal activation and early treatment with enalapril (CONSENSUS II) following myocardial infarction. Eur Heart J. 1994, 15:14-9.

9. Lilly LS, Dzau VJ, Williams GH, Rydstedt L, Hollenberg NK: Hyponatremia in congestive heart failure: implications for neurohumoral activation and responses to orthostasis. J Clin Endocrinol Metab. 1984, 59:924-30.

10. Abebe TB, Gebreyohannes EA, Tefera YG, et al.: The prognosis of heart failure patients: Does sodium level play a significant role?. PLoS One. 2018, 13:e0207242. Accessed: September 15, 2019: 10.1371/journal.pone.0207242

11. Hiki M, Kasai T, Yatsu S, et al.: Relationship between serum sodium level within the low-normal range on admission and long-term clinical outcomes in patients with acute decompensated heart failure. Int Heart J. 2018, 59:1052-1058. 10.1536/ihj.17-524

12. Choi JS, Kim CS, Bae EH, et al.: Choi JS, Kim CS, Bae EH, Ma SK, Ahn YK, Jeong MH, Kim SW . Medicine (Baltimore). 2017, 96:e7023. 10.1097/MD.0000000000007023

13. Avcı BK, Küçük M, Müderrisoğlu H, et al.: Relation between serum sodium levels and clinical outcomes in Turkish patients hospitalized for heart failure: a multi-center retrospective observational study. Anatol J Cardiol. 2017, 17:2-7. 10.14744/AnatolJCardiol.2016.6950

14. Donzé JD, Beeler PE, Bates DW: Impact of hyponatremia correction on the risk for 30-day readmission and death in patients with congestive heart failure. Am J Med. 2016, 129:836-42. 10.1016/j.amjmed.2016.02.036

15. Radulović B, Potočnjak I, Dokoza Terešak S, et al.: Hypochloraemia as a predictor of developing hyponatraemia and poor outcome in acute heart failure patients. Int J Cardiol. 2016, 212:237-41. 10.1016/j.ijcard.2016.03.081

16. Lu DY, Cheng HM, Cheng YL, et al.: Hyponatremia and worsening sodium levels are associated with longterm outcome in patients hospitalized for acute heart failure. J Am Heart Assoc. 2016, 5:e002668. Accessed: September 15, 2019: 10.1161/JAHA.115.002668

17. Yoshioka K, Matsue Y, Kagiyama N, et al.: Recovery from hyponatremia in acute phase is associated with better in-hospital mortality rate in acute heart failure syndrome. J Cardiol. 2016, 67:406-11. 10.1016/j.jjcc.2015.12.004

18. Saepudin S, Ball PA, Morrissey H: Hyponatremia during hospitalization and in-hospital mortality in patients hospitalized from heart failure. BMC Cardiovasc Disord. 2015, 15:88. 10.1186/s12872-015-0082-5

19. Méndez-Bailón M, Barba-Martín R, de Miguel-Yanes JM, et al.: Hyponatremia in hospitalised patients with heart failure in internal medicine: Analysis of the Spanish national minimum basic data set (MBDS) (20052011). Eur J Intern Med. 2015, 26:603-6. 10.1016/j.ejim.2015.06.009

20. Burkhardt K, Kirchberger I, Heier M, et al.: Hyponatraemia on admission to hospital is associated with increased long-term risk of mortality in survivors of myocardial infarction. Eur J Prev Cardiol. 2015, 22:1419-26. 10.1177/2047487314557963

21. Yoo BS, Park JJ, Choi DJ, et al.: Prognostic value of hyponatremia in heart failure patients: an analysis of the Clinical Characteristics and Outcomes in the Relation with Serum Sodium Level in Asian Patients Hospitalized for Heart Failure (COAST) study. Korean J Intern Med. 2015, 30:460-70. 10.3904/kjim.2015.30.4.460

22. Bavishi C, Ather S, Bambhroliya A, et al.: Prognostic significance of hyponatremia among ambulatory patients with heart failure and preserved and reduced ejection fractions. Am J Cardiol. 2014, 113:1834-8. 10.1016/j.amjcard.2014.03.017

23. Arévalo Lorido JC, Carretero Gómez J, Formiga F, et al.: Hyponatremia as predictor of worse outcome in real world patients admitted with acute heart failure. Cardiol J. 2013, 20:506-12. 10.5603/CJ.2013.0136

24. Qureshi W, Hassan S, Khalid F, et al.: Outcomes of correcting hyponatremia in patients with myocardial infarction. Clin Res Cardiol. 2013, 102:637-44. 10.1007/s00392-013-0576-Z

25. Sato N, Gheorghiade M, Kajimoto K, et al.: Hyponatremia and in-hospital mortality in patients admitted for heart failure (from the ATTEND registry). Am J Cardiol. 2013, 111:1019-25. 10.1016/j.amjcard.2012.12.019

26. Lazzeri C, Valente $\mathrm{S}$, Chiostri M, Attanà $\mathrm{P}$, Picariello C, Gensini GF: Usefulness of hyponatremia in the acute phase of ST-elevation myocardial infarction as a marker of severity. Am J Cardiol. 2012, 110:1419-24. 10.1016/j.amjcard.2012.07.004

27. Deubner N, Berliner D, Frey A, et al.: Dysnatraemia in heart failure . Eur J Heart Fail. 2012, 14:1147-54 10.1093/eurjhf/hfs115

28. Baldasseroni S, Urso R, Orso F, et al.: Relation between serum sodium levels and prognosis in outpatients with chronic heart failure: neutral effect of treatment with beta-blockers and angiotensin-converting enzyme inhibitors. J Cardiovasc Med (Hagerstown). 2011, 12:723-31. 10.2459/JCM.0b013e32834ae87e

29. Balling L, Schou M, Videbæk L, et al.: Prevalence and prognostic significance of hyponatraemia in outpatients with chronic heart failure. Eur J Heart Fail. 2011, 13:968-73. 10.1093/eurjhf/hfr086

30. Shorr AF, Tabak YP, Johannes RS, et al.: Burden of sodium abnormalities in patients hospitalized for heart failure. Congest Heart Fail. 2011, 17:1-7. 10.1111/j.1751-7133.2010.00206.x

31. Tang Q, Hua Q: Relationship between hyponatremia and in-hospital outcomes in Chinese patients with STelevation myocardial infarction. Intern Med. 2011, 50:969-74. 10.2169/internalmedicine.50.4703

32. Mohammed AA, van Kimmenade RR, Richards M, et al.: Hyponatremia, natriuretic peptides, and outcomes in acutely decompensated heart failure. Circ Heart Fail. 2010, 3:354-61. 10.1161/CIRCHEARTFAILURE.109.915280

33. DeWolfe A, Lopez B, Arcement LM, Hebert K: Low serum sodium as a poor prognostic indicator for mortality 
in congestive heart failure patients. Clin Cardiol. 2010, 33:E13-7. 10.1002/clc.20560

34. Formiga F, Chivite D, Brasé A, Petit I, Moreno-Gonzalez R, Arévalo-Lorido JC, Corbella X: Clinical characteristics and prognosis in patients with a first acute heart failure hospitalization according to admission hyponatremia. Acta Clin Belg. 2018, 73:281-286. 10.1080/17843286.2018.1429345

35. Elfar A, Sambandam KK: The basic metabolic profile in heart failure-marker and modifier . Curr Heart Fail Rep. 2017, 14:311-320. 10.1007/s11897-017-0344-X

36. Ma QQ, Fan XD, Li T, et al.: Short- and long-term prognostic value of hyponatremia in patients with acute coronary syndrome: A systematic review and meta-analysis. PLoS One. 2018, 13:e0193857. 10.1371/journal.pone.0193857

37. Bettari L, Fiuzat M, Felker GM, O'Connor CM: Significance of hyponatremia in heart failure . Heart Fail Rev. 2012, 17:17-26. 10.1007/s10741-010-9193-3

38. Rusinaru D, Tribouilloy C, Berry C, et al.: Relationship of serum sodium concentration to mortality in a wide spectrum of heart failure patients with preserved and with reduced ejection fraction: an individual patient data meta-analysis. Eur J Heart Fail. 2012, 14:1139-46.

39. Tada Y, Nakamura T, Funayama H, et al.: Early development of hyponatremia implicates short- and longterm outcomes in ST-elevation acute myocardial infarction. Circ J. 2011, 75:1927-33.

40. Bhavnani SP, Kumar A, Coleman CI, Guertin D, Yarlagadda RK, Clyne CA, Kluger J: The prognostic impact of pre-implantation hyponatremia on morbidity and mortality among patients with left ventricular dysfunction and implantable cardioverter-defibrillators. Europace. 2014, 16:47-54. 10.1093/europace/eut211

41. Kusaka H, Sugiyama S, Yamamoto E, et al.: Low-normal serum sodium and heart failure-related events in patients with heart failure with preserved left ventricular ejection fraction. Circ J. 2016, 80:411-7. 10.1253/circj.CJ-15-0878

42. Arao K, Fujiwara T, Sakakura K, et al.: Hyponatremia as a predictor for worsening heart failure in patients receiving cardiac resynchronization therapy. Circ J. 2013, 77:116-22.

43. Schou M, Valeur N, Torp-Pedersen C, Gustafsson F, Køber L: Plasma sodium and mortality risk in patients with myocardial infarction and a low LVEF. Eur J Clin Invest. 2011, 41:1237-44. 10.1111/j.13652362.2011.02532.x

44. Matsue Y, Yoshioka K, Suzuki M, et al.: Prognostic importance of sodium level trajectory in acute heart failure. Heart Vessels. 2017, 32:1498-1505. 10.1007/s00380-017-1020-5

45. Omar HR, Guglin M: Rise of first follow-up sodium in patients hospitalized with acute heart failure is associated with better outcomes. Int J Cardiol. 2018, 269:201-206. 10.1016/j.ijcard.2018.06.071

46. Kitai T, Grodin JL, Kim YH, Tang WH: Impact of ultrafiltration on serum sodium homeostasis and its clinical implication in patients with acute heart failure, congestion, and worsening renal function. Circ Heart Fail. 2017, 10:e003603. 10.1161/CIRCHEARTFAILURE.116.003603

47. Colin-Ramirez E, McAlister FA, Zheng Y, et al.: The long-term effects of dietary sodium restriction on clinical outcomes in patients with heart failure. Am Heart J. 2015, 169:274-281.e1. 10.1016/j.ahj.2014.11.013

48. Omar HR, Guglin M: Community acquired versus hospital acquired hyponatremia in acute heart failure: Association with clinical characteristics and outcomes. Int J Cardiol. 2016, 225:247-49.

10.1016/j.ijcard.2016.09.135 